\title{
DESNATURALIZANDO O GÊNERO E A SEXUALIDADE
}

\author{
DENATURALIZING GENDER AND SEXUALITY
}

\author{
Bento Manoel Jesús ${ }^{1}$
}

Recebido em: 07/03/2013 Aprovado em: 25/03/2014

\section{RESUMO}

A pretensão deste trabalho é analisar teoricamente uma questão que, nas últimas décadas, tem sido consideravelmente discutida nas ciências sociais: a concepção de que o gênero e a sexualidade são categorias socialmente construídas e não elementos essencialmente determinados por fatores biológicos ou psicológicos. O objetivo deste texto é discutir essa questão a partir de algumas ideias defendidas pelos estudos de gênero e sexualidade nas ciências sociais, pelo pensamento feminista e pela teoria queer, destacando, principalmente, os argumentos que alguns autores utilizam para explicitar o caráter social das referidas categorias, especialmente no que diz respeito a aspectos de manutenção e de transformação da ordem social. Palavras-chave: Gênero; Sexualidade; Construção social.

\section{Introdução}

Este trabalho é oriundo das discussões desenvolvidas em minha dissertação de mestrado, pesquisa inscrita na arena dos saberes sobre identidades de gênero, que teve como tema a transexualidade e como objetivo situar o debate sobre a despatologização da transexualidade no Brasil, analisando seus campos discursivos. No decorrer da pesquisa, ao adentrar nas discussões teóricas sobre gênero e sexualidade pelo viés das ciências sociais, percebi a recorrência de problematizações em torno da questão da naturalização e desnaturalização das identidades. Mas, o que significa desnaturalizar? E o que significa naturalizar?

Um dos significados do termo natureza remete à ideia de tudo aquilo

\begin{abstract}
The intention of this paper is to analyze theoretically an issue that in recent decades has been considerably discussed in social sciences: the idea that gender and sexuality are socially constructed categories, instead of elements essentially determined by biological or psychological factors. The aim of this paper is to discuss this issue from some ideas espoused by studies of gender and sexuality in the social sciences, by feminism and queer theory, emphasizing particularly the arguments that some authors use to explain the social character of these categories, especially with regard to aspects of maintenance and transformation of the social order.
\end{abstract}

Keywords: Gender; Sexuality; Social construction.

cuja existência é regida por leis próprias. De acordo com essa noção, a qualidade de natural diz respeito a algo que é inerente, a uma essência que faz com que determinada coisa seja o que ela é. Assim, tanto naturalizar quanto desnaturalizar são situações que não ocorrem de fato, pois não é possível inserir uma essência em algo ou destituí-lo de uma. No sentido aqui empregado, naturalizar significa atribuir qualidades essenciais ao que, na verdade, é fruto de atividades humanas, enquanto que desnaturalizar significa explicitar o caráter social de fenômenos concebidos como naturais.

Em se tratando de gênero e sexualidade, a biologia concebe esses elementos como naturais no sentido estrito, isto é, como predeterminados por fatores de ordem orgânica e/ou psicológica. Entretanto, essa vertente é contraposta por ou-

${ }^{1}$ Mestrando do Programa de Pós-Graduação em Sociologia da Universidade Federal de Goiás, Brasil. E-mail: bento_70@hotmail.com. 
tras linhas de pensamento, como os estudos de gênero e sexualidade nas ciências sociais, o feminismo e a teoria queer, que argumentam que o gênero e a sexualidade são categorias socialmente construídas. Assim, o objetivo deste trabalho é analisar teoricamente essa questão a partir dos pontos de vista desses campos de conhecimento, com destaque para os argumentos que refutam a naturalidade das referidas categorias, especialmente em relação a aspectos de manutenção e de transformação da ordem social.

Espero que este trabalho, focado na questão da desnaturalização, possa contribuir com os estudos de gênero e sexualidade nas ciências sociais, especialmente por seu caráter introdutório a uma questão que, sendo central nesses estudos, certamente será de interesse para os iniciantes nessas áreas de conhecimento. Ademais, mesmo que de forma incipiente, o texto traz questões importantes para o entendimento das relações sociais que envolvem gênero e sexualidade, como os fatores culturais e a política.

\section{A desnaturalização da "natureza"}

A sexualidade é o objeto de estudos de vertentes teóricas de diversas áreas da ciência. No caso das ciências sociais, a antropologia foi a primeira disciplina a tomar a sexualidade como objeto de investigação científica. Em seus primórdios, os estudos antropológicos sobre o tema sofreram forte influência, sobretudo, das noções de essencialismo e universalidade de conceitos biomédicos e psicanalíticos que relacionavam a sexualidade com as ideias de instinto e pulsão. Posteriormente, a antropologia superou essa visão de sexualidade ao enfatizar o papel das culturas e das aprendizagens na formação das condutas sexuais e ao perceber que tais condutas diversificam-se enormemente entre culturas, gerações, contextos geográficos, grupos e classes sociais (SZASZ, 2004).

Segundo a mesma autora, após a inauguração pela antropologia, os estudos sobre sexualidade nas ciências sociais ganharam campo e passaram a ser influenciados principalmente pelo pensamento feminista, pelos estudos lésbico-gays, pelo interacionismo simbólico, pela sociologia do conhecimento, pela teoria pós-estruturalista e pela crítica anticolonialista. Vale ressaltar que, atualmente, a teoria queer também tem exercido grande influência nesses estudos.

Esse arsenal teórico é base do argumento de que a sexualidade não é apenas influenciada, mas construída nas e pelas relações sociais. Nessa linha de pensamento, o conceito de sexualidade é ampliado, não se restringindo à ideia de um impulso relacionado a partes ou funções específicas do corpo. Assim, considera, além dos atributos que envolvem o corpo - tais como os desejos eróticos, as fantasias, as sensações, as práticas e os hábitos -, as relações sociais, as concepções, os valores, os discursos e toda a rede de significados construídos em torno dos desejos e das condutas sexuais ${ }^{2}$.

Essa perspectiva teórica que renega o essencialismo é geralmente chamada de construtivismo social. Conforme salienta Heilborn (1999), tal perspectiva não tem uma posição única em relação à sexualidade, pois possui desdobramentos. Conforme a antropóloga americana Carole Vance, um primeiro desdobramento seria denominado de modelo de influência cultural, condizendo às proposições supracitadas de Szasz (2004). Esse modelo refuta o determinismo biológico, mas permite que dados da biologia coexistam com aspectos da personalidade e do comportamento, sendo a pulsão sexual conformada de acordo com cada sociedade.

Já o segundo desdobramento do construtivismo social proposto por $\mathrm{Ca}$ role Vance e citado por Heilborn (1999) teria um caráter mais radical. Esse modelo rejeita qualquer substrato de ordem biológica e/ou psicológica em relação à 
sexualidade que possa ser considerado universal. Para essa linha de pensamento, o domínio do sexual, incluindo as sensações corpóreas, é efeito de construções culturais.

São posicionamentos teóricos que compartilham certos pressupostos e divergem em outros. Na linha do modelo de influência cultural é que eclodiram mais discussões em torno da distinção entre sexo e gênero, como o ensaio The Traffic in Women: Notes on the "Political Economy" of Sex ${ }^{3}$, de autoria da antropóloga estadunidense Gayle Rubin. Nesse texto, a autora desenvolve o conceito de "sistema de sexo/gênero", o qual define como "el conjunto de disposiciones por el que una sociedad transforma la sexualidad biológica en productos de la actividad humana, y en el cual se satisfacen esas necesidades humanas transformadas" (RUBIN, 1986, p. 97).

Segundo a autora, o "sistema de sexo/gênero" não se restringe às relações de procriação em um sentido biológico, mas, uma vez fazendo parte de uma complexa rede social, define-se por inumeráveis articulações econômicas e políticas relacionadas a questões como parentesco, casamento e divisão do trabalho. Em outras palavras, tratase de um conjunto de relações sociais que transforma as diferenças biológicas (diferenças sexuais inatas) entre homens e mulheres em produtos da atividade humana, muitos dos quais se cristalizam e são vistos como se fossem naturais (RUBIN, 1986).

Do ponto de vista da autora, o gênero se traduziria no que é produzido e transformado a partir de um elemento biológico imutável: o sexo. Nessas proposições, o gênero já não tem mais uma "natureza" orgânica como se supunha, embora dependa de uma base biológica para operar. Segundo Rubin, a simples condição de nossa espécie ser ca-

${ }_{3}^{3}$ The Traffic in Women data de 1975, quando Gayle Rubin ainda era uma estudante de mestrado. Nesse trabalho, ela se propôs a problematizar a questão da subordinação feminina através de uma "exegese" dos trabalhos de Lévi-Strauss e Sigmund Freud. racteristicamente social, de estabelecer culturas e articulações, impossibilita a existência de uma vida sexual humana isenta de influências contextuais e de convenções e intervenções humanas ${ }^{4}$.

$\mathrm{O}$ gênero, ao ser concebido como um construto cultural das diferenças entre homens e mulheres, envolve relações de poder, tornando-se uma categoria política e analítica e sendo, por isso, um conceito tão caro às feministas. Conforme Piscitelli (2002), o conceito de gênero foi elaborado em um momento específico da história das teorias sociais sobre a questão da "diferença sexual". Em sua trajetória, tal conceito já esteve relacionado a estudos sobre a mulher e nunca deixou de ser reelaborado:

$\mathrm{Na}$ atualidade é comum opor os "estudos sobre mulher" aos "estudos de gênero". Ao mesmo tempo, ainda é freqüente a confusão entre "gênero" e "mulher". As duas situações são compreensíveis quando se pensa na história do pensamento feminista. Quero dizer que o conceito de gênero se desenvolveu no marco dos estudos sobre "mulher" e compartilhando vários dos seus pressupostos (PISCITELLI, 2002, p. 13-14).

Por sua vez, Haraway (2004) pontua que, se, por um lado, o conceito de gênero "foi desenvolvido como uma categoria para explorar o que significa 'mulher', para problematizar o que era anteriormente dado" (HARAWAY, 2004 , p. 245), por outro, foi duramente criticado por seu caráter genérico. Segundo a autora, as críticas vieram especialmente de mulheres negras e/ou lésbicas que não se viram contempladas pelo conceito de gênero produzido por mulheres ocidentais brancas.

Assim, o conceito de gênero deixou de focalizar a "mulher" e passou a se referir às diferenças socialmente construídas entre homens e mulheres, defendendo a proposta de se pensar em "mulheres" e "homens" ao invés de "mu- 
lher". Contribuindo com essa discussão, Scott (1995) vai argumentar a favor de uma redefinição e reestruturação do gênero baseadas em uma visão de igualdade política e social que leve em conta a interseccionalidade das categorias sexo, classe e raça. Do ponto de vista da autora, trata-se de um processo político cuja história só poderá ser escrita

[...] se reconhecermos que "homem" e "mulher" são, ao mesmo tempo, categorias vazias e transbordantes. Vazias, porque não têm nenhum significado último, transcendente. Transbordantes, porque mesmo quando parecem estar fixadas, ainda contêm dentro delas definições alternativas, negadas ou suprimidas (SCOTT, 1995, p. 93).

Pelo argumento de Scott, podese considerar que o caráter inacabado do conceito de gênero se justifica pelo fato de "homem" e "mulher" não serem categorias fechadas, uma vez que essas definições, assim como o que se entende por masculinidade e feminilidade, são interpretações idealizadas e sujeitas a contingências, conforme exemplificam algumas pesquisas sobre masculinidade propriamente dita.

Vale de Almeida (1995) considera que a masculinidade hegemônica é uma idealização, não sendo alcançada por praticamente nenhum homem. Segundo o autor, é questionável o uso do termo masculinidade no singular, uma vez que as diversas experiências e identidades dos homens sinalizam a existência de várias masculinidades. Já para Connell (1995), os próprios padrões de masculinidade hegemônica mudam com o tempo, o que faz com que as masculinidades devam ser analisadas a partir de uma perspectiva histórica.

O que se sabe, é que as pesquisas sobre as diferenças entre homens e mulheres remontam a épocas anteriores ao conceito de gênero, como é o caso dos estudos da antropóloga Margaret Mead. Em Sexo e temperamento (1979), a autora propôs-se a corroborar a proposi- ção de que é a cultura que produz as maneiras como homens e mulheres se posicionam objetiva e subjetivamente e de que o "temperamento" não dependeria do sexo, conforme mostram as conclusões da pesquisa.

De três comunidades tribais observadas por Mead, duas produziam identidades que não se diferiam entre homens e mulheres: a diferença entre eles era que um se caracterizava por condutas pacíficas entre seus membros, enquanto que o outro se distinguia por condutas altamente agressivas. O terceiro grupo produzia identidades distintas entre homens e mulheres, porém divergentes da hegemonia ocidental homem-ativo/mulher-passiva, pois, entre eles, essa lógica se invertia para mulher -ativa/homem-passivo (MEAD, 1979).

É nesse sentido que qualquer compreensão do lugar e das relações entre homens e mulheres em uma sociedade deve ser feita a partir das construções sociais sobre os sexos e não em relação às características sexuais propriamente ditas. Como lembra Louro (1997), as formas de condutas legitimadas como masculinas ou femininas não advêm da diferença sexual biológica, mas das concepções, das representações ou das valorizações atribuídas às características sexuais.

Para Piscitelli (2009), o problema está no fato de que muitas das naturalizações engendradas a partir da diferença sexual são tomadas para produzir ou sustentar desigualdades sociais, que, por sua vez, também são naturalizadas. A esse respeito, a autora destaca:

O termo gênero, em suas versões mais difundidas, remete a um conceito elaborado por pensadoras feministas precisamente para desmontar esse duplo procedimento de naturalização mediante o qual as diferenças que se atribuem a homens e mulheres são consideradas inatas, derivadas de distinções naturais, e as desigualdades entre uns e outras são percebidas como resultado dessas diferenças (PISCITELLI, 2009, p. 119). 
É por isso que a perspectiva do construcionismo social, segundo Weeks (2007), busca compreender a diversidade de relações de poder que modelam o que vem a ser aceito ou refutado socialmente. Essa perspectiva não está interessada nas causas dos fenômenos, mas na compreensão do modo como são construídas as hierarquias e do porquê de certas categorias e práticas serem privilegiadas enquanto que outras são marginalizadas pela cultura.

Foi nesse sentido que Gayle Rubin produziu o artigo Thinking Sex: Notes for a Radical Theory of the Politics of Sexuality, no qual se posiciona de forma diferente em relação ao assunto, propondo um novo sistema sexo/gênero. O sexo já não é visto como o elemento natural a partir do qual o gênero opera, apesar de estarem interligados. Nesse artigo, a autora discute a diversidade sexual a partir de um sistema hierárquico de valor sexual, no qual a heterossexualidade, com base em uma suposta naturalidade, é considerada como "boa" e "normal". A sexualidade ideal, além de heterossexual, se exerceria no casamento, seria monogâmica, reprodutiva e isenta de prostituição. Por outro lado, qualquer forma de sexualidade ou prática que viesse a violar esses preceitos, como exemplo, a homossexualidade, a prostituição ou o sexo fora do matrimônio, seria considerada "antinatural", "má" e "anormal" (RUBIN, 1989).

Em síntese, enquanto que as experiências heterossexuais são moralmente aceitas, as chamadas sexualidades dissidentes são consideradas perigosas, repulsivas e desprovidas de qualquer teor emocional. Os seus praticantes sofrem severas restrições sociais, podendo até ser vistos como enfermos mentais ou pessoas propensas à criminalidade. Para muitas religiões, toda conduta erótica é considerada má e pecaminosa, a menos que seu praticante se redima por meio de alguns atributos conferidos à heterossexualidade, como o matrimônio, a reprodução e o amor ${ }^{5}$.

Assim, Gayle Rubin integra um grupo de cientistas para o qual gênero e sexualidade têm menos a ver com natureza do que com regulamentações sociais. Essa corrente construcionista se pauta especialmente na história e nas diferenças contextuais para fundamentar seus argumentos, tendo nos trabalhos de Michel Foucault uma de suas principais referências. Defendendo a ideia de um dispositivo que produz discursos verdadeiros sobre o sexo, Foucault (1988) afirma que a sexualidade não é predeterminada por fatores biológicos, mas socialmente construída no decorrer do processo histórico.

A noção de dispositivo cunhada por Foucault (1985) compreende uma conexão entre inúmeros elementos altamente heterogêneos, como discursos, concepções, instituições, legislações, proposições científicas e filosóficas, moralidades e organizações arquitetônicas. A principal função dessa conexão é responder a uma urgência, a uma questão de um determinado momento histórico. A proposição de Foucault é que, a partir do século XVIII, houve uma proliferação de discursos sobre o sexo mediados estrategicamente por instituições como a igreja, a escola e a medicina. Esses discursos deveriam ser úteis e públicos e terem como objetivo não a proibição, mas a regulamentação do sexo.

Assim, a concepção foucaultiana de poder está no centro do pensamento construcionista. O poder para Foucault não consiste em uma substância, mas em relações estratégicas e instáveis. Dessa forma, o poder não é propriedade de alguém particular, se direcionando em sentido único, do opressor ao oprimido, mas é dinâmico, mesmo que distribuído desigualmente. Como se trata de dinâmica, a resistência ao poder é produzida por ele próprio, como parte de suas relações, de forma que onde se tem poder também se tem resistência. Para Foucault, o poder não se resume 
a proibições e obrigações, mas é também produtivo, especialmente quanto às próprias possibilidades de interações (HALPERIN, 2004).

A compreensão foucaultiana de sexualidade como uma construção social e histórica está na base do que veio a ser chamado de teoria queer. Conforme pontua Richard Miskolci, a teoria queer é oriunda dos Estudos Culturais e surgiu nos Estados Unidos no final da década de 1980. Apresentando-se como oposição crítica aos estudos sociológicos sobre minorias sexuais e gênero, a teoria queer elegeu como objeto de estudo a dinâmica da sexualidade e do desejo na organização das relações sociais contemporâneas (MISKOLCI, 2009).

A filósofa estadunidense Judith Butler, cuja obra foi acolhida como uma das precursoras e expoentes dessa vertente teórica, traz a seguinte definição para queer:

O termo queer surge como uma interpelação que discute a questão da força e da oposição, da estabilidade e da variabilidade no seio da performatividade. Esse termo tem operado como uma prática linguística cujo propósito tem sido o da degradação do sujeito a que se refere, ou melhor, a constituição desse sujeito mediante esse apelativo degradante. Queer adquire todo seu poder precariamente através da evocação reiterada que o relaciona com acusações, patologias e insultos (BUTLER, 2002 apud BENTO, 2006, p. 80-81, grifo no original).

No pensamento queer, a degradação não é rejeitada pelo sujeito que a recebe, mas é reapropriada para que seja possível questionar o próprio sistema normalizador que the confere a degradação. Trata-se de uma postura de rompimento com a ordem heterossexual, que impõe uma coerência entre sexo, gênero e sexualidade. No sistema normalizador, as práticas e os sujeitos que não correspondem a essa coerência não são considerados inteligíveis
(BUTLER, 2005).

O que Butler argumenta é que não somente o gênero e a sexualidade são socialmente construídos, mas também o próprio sexo. Segundo ela, as sociedades estabelecem normas que regulam e materializam o sexo dos sujeitos, prescrevendo que, para os corpos serem inteligíveis, eles necessitam de um sexo e de um gênero estáveis. Entretanto, a autora salienta que os corpos nunca se moldam inteiramente às normas pelas quais sua materialização é obrigada; não alcançam o ideal que lhes é imposto. Por isso, tais normas são constantemente reiteradas e reconhecidas na tentativa de que a materialização desejada se efetive. Essas normas são performativas, ou seja, possuem um poder contínuo e renovado de produzir exatamente o que se nomeia ${ }^{6}$.

A ideia de performatividade é retirada das proposições de Austin (1990) sobre a capacidade da linguagem para criar verdades. Conforme esse autor, a função da linguagem não é simplesmente descrever a realidade, mas também produzir realidades. Assim, Butler propõe a ideia de um processo de reiteração performativo que produz a heterossexualidade como norma, mas que também produz os corpos que escapam a essa normalização, aos quais ela chama de corpos "abjetos". O abjeto é o sujeito degradado, o contraponto do normal, a referência necessária para que o normal possa se instituir como tal ${ }^{7}$.

A oposição da teoria queer aos estudos sobre minorias sexuais e gênero decorre, segundo Miskolci (2009), do fato de que esses estudos ainda não romperam completamente com o pressuposto de normalidade, de modo que acabam por manter e naturalizar a norma heterossexual. Segundo o autor,

[...] ao invés de priorizar investigações sobre a construção social de identidades, estudos empíricos sobre comportamentos sexuais que levem a 
classificá-los ou compreendê-los, os empreendimentos queer partem de uma desconfiança com relação aos sujeitos sexuais como estáveis e foca nos processos sociais classificatórios, hierarquizadores, em suma, nas estratégias sociais normalizadoras dos comportamentos (MISKOLCI, 2009, p. 169).

Assim, a teoria queer tem um posicionamento antinormativo em relação à sexualidade, pois pretende, especialmente, embaralhar e confundir as categorias que legitimam a normatividade social. Ao se recusar a classificar as pessoas em categorias, o pensamento queer dá existência às diversas culturas sexuais, não no sentido de identidade, mas de possibilidades de experiências (VALE DE ALMEIDA, 2004).

Ao refutar a classificação das pessoas em categorias, a perspectiva queer se contrapõe ao pensamento das vertentes políticas, pois, para estas, o importante é que as identidades sejam assumidas e que busquem a legitimidade e o reconhecimento. Dessa forma, ao propor a conversão das identidades em um "sem sentido" e recusar a ideia de categorias estáveis, a teoria queer parece levantar um dilema em relação à forma convencional de posicionamento político (GAMSON, 2002).

Entretanto, Miskolci (2009) vai argumentar que o papel da vertente queer não é o de desqualificar os movimentos sociais identitários. Segundo o autor, a proposta dessa vertente é apontar as armadilhas hegemônicas nas quais esses movimentos estão inseridos, assim como permitir a formação de alianças estratégicas entre os movimentos que compartilham o objetivo de criticar e contestar os regimes normalizadores, que produzem tanto as identidades quanto a posição que elas vão ocupar na sociedade.

\section{Considerações finais}

Pelas análises dos autores supra- citados, a desnaturalização do gênero e da sexualidade é importante porque questiona a ideia de naturalidade que confere à heterossexualidade um lugar de privilégio no social. Quando Butler diz que "talvez o próprio construto chamado 'sexo' seja tão culturalmente construído quanto o gênero" (BUTLER, 2003 , p. 25), ela está se referindo à performatividade, ao poder do discurso de criar verdades. Ao se entender o sexo como um dado natural, descarta-se a possibilidade de compreendê-lo enquanto algo socialmente produzido por outra construção social, que é a ciência chamada biologia, condizente com o pensamento hegemônico normalizador.

Ao se estudar as categorias gênero e sexualidade a partir de um enfoque social, não é apenas o conhecimento sobre elas que se amplia, mas também o conhecimento sobre outros diversos elementos sociais com os quais elas se relacionam. O que fica claro nas leituras das diferentes análises dos autores é que as discussões sobre esses temas não se findam. No entanto, essas intermináveis discussões podem abrir possibilidades de transformações que superem as desigualdades sociais vinculadas ao gênero e à sexualidade.

\section{Referências}

1. AUSTIN, J. L. Quando dizer é fazer: palavras e ação. Tradução Danilo Marcondes de Souza Filho. Porto Alegre: Arte Médicas, 1990.

2. BENTO, B. A reinvenção do corpo: sexualidade e gênero na experiência transexual. Rio de Janeiro: Garamond, 2006.

3. BUTLER, J. Cuerpos que importam: sobre los limites materiales $y$ discursivos del "sexo". Buenos Aires: Paidós, 2005, p. 17-49 e 179-203.

4. Problemas de gênero - feminismo e subversão da identidade. Rio de Janeiro: Civilização Brasileira, 2003. 
5. CONNELL, R. W. Políticas da masculinidade. In: Educação e Realidade, 20 (2). Porto Alegre: UFRGS, 1995.

6. FOUCAULT, M. História da sexualidade I: a vontade de saber. Tradução Maria Thereza da Costa Albuquerque e J. A. Guilhon Albuquerque. Rio de Janeiro: Graal, 1988.

7. Sobre a história da sexualidade. In: Microfísica do poder. Rio de Janeiro: Graal, 1985, p. 243-276.

8. GAMSON, J. Deven autodestuirse los movimientos identitários? Um extraño dilema. In: JIMÉNEZ, R. M. M. (Ed.). Sexualidades transgresoras: uma antologia de estúdios queer. Barcelona: Icaria, 2002, p. 141-172.

9. HALPERIN, D. La política queer de Michel Foucault. In: San Foucault - para uma hagiografia gay. Córdoba: Ediciones Liberales, 2004, p. 35-145.

10. HARAWAY, D. “Gênero' para um dicionário marxista: a política sexual de uma palavra". In: Cadernos Pagu (22). Campinas: Unicamp, 2004.

11. HEILBORN, M. L.; BRANDÃO, E. R. "Introdução: Ciências Sociais e Sexualidade". In: HEILBORN, Maria Luiza (org.). Sexualidade: o olhar das ciências sociais. IMS/UERJ. Rio de Janeiro: Editora Zahar, 1999, p. 7-17.

12. LOURO, G. L. Gênero, sexualidade e educação: uma perspectiva pós-estruturalista. Petrópolis: Vozes, 1997.

13. MEAD, M. Sexo e temperamento. $2^{\mathrm{a}}$ Ed. São Paulo: Perspectiva, 1979.

14. MISKOLCI, R. A Teoria Queer e a Sociologia: o desafio de uma analítica da normalização. In: Sociologias, no 21 . Porto Alegre: UFRGS, 2009, p. 150182.

15. PISCITELLI, A. Gênero: a história de um conceito. In: ALMEIDA, Heloisa Buarque de; SZWAKO, José (Orgs.).
Diferenças, igualdade. São Paulo: Berlendis \& Vertecchia, 2009, (Coleção sociedade em foco: introdução às ciências sociais).

16. Re-criando a (categoria) mulher? In: ALGRANTI, Leila Mezan (Org). A prática feminista e o conceito de gênero. Campinas: IFCH - Unicamp, 2002 (Coleção Textos Didáticos).

17. RUBIN, G. El Tráfico de Mujeres: notas sobre la "economía política" del sexo. In: Revista Nueva Antropología, vol. 8, n 30. México: UNAM, 1986, p. 95-145.

18. Reflexionando sobre el sexo: notas para uma teoria radical de la sexualidad. In: VANCE, Carole, (comp). Placer y peligro. Explorando la sexualidad femenina. Madrid: Revolución, 1989, p. 113-190.

19. SCOTT, J. "Gênero: uma categoria útil de análise histórica". In: Educação \& Realidade, v. 20, n. 2. Porto Alegre: UFRGS, 1995.

20. SZASZ, I. El discurso de las ciências sociales sobre las sexualidades. In: CÁCERES, C. F. (Eds.). Cidadania sexual em América Latina: abriendo el debate. Lima, Universidade Peruana Cayetano Herida, 2004, p. 65-75.

21. VALE DE ALMEIDA, M. A teoria queer e a construção da categoria "gênero". In: CASCAIS, A. (org). Indisciplinar a teoria - estudos gays, lésbicos e queer. Lisboa: Fenda Edições, 2004, p. 91-98.

22. Senhores de si - uma interpretação antropológica da masculinidade. Lisboa: Fim de Século, 1995.

23. WEEKS, J. O corpo e a sexualidade. In: LOURO, Guacira L. (Org.). O corpo educado: pedagogias da sexualidade. Tradução Tomaz Tadeu da Silva. Belo Horizonte: Autêntica, 2007. 